\title{
Rebuilding the City: A Focus for European Industrial Policy? ${ }^{1}$ David Bailey and Keith Cowling ${ }^{2}$
}

\begin{abstract}
While the city offers the potential of dynamic agglomeration economies which can spur the achievement of economic growth and act as an engine that powers the economy, it often appears as a centre of crisis in mature 'developed' regions and countries, even before the most recent economic downturn. This paper attempts to reconcile these two seemingly paradoxical observations by bringing in a strategic choice perspective to explain how concentrated strategic decision-making in the corporate entities that dominate our cities has diminished the very diversity that Jacobs identified as being essential for cities to flourish and develop. The industrial policy implications for cities are subsequently explored in terms of building new industrial districts, developing high skill ecosystems, and fostering multinational webs of cities, all with the aim of ensuring the conditions exist in cities for creativity and development to flourish, notably a diverse and democratic economic system.
\end{abstract}

Keywords: Cities, industrial policy, transnationals, strategic choice, governance, economic development.

"Cities concentrate poverty, but they also represent the best hope of escaping it" (UN Population Fund, 2007).

"Cities have the capability of providing something for everybody, only because and only when they are created by everybody" (Jane Jacobs, 1984: 251).

\section{Introduction: A Tale of Two Cities? Engines of Growth, yet in Crisis.}

While the city offers the potential of dynamic agglomeration economies which can spur the achievement of economic growth and act as an engine that powers the economy

\footnotetext{
${ }^{1}$ Thanks to Kurt Rothschild and Roger Sugden for significant comments on earlier versions of this paper, and to participants at various presentations, most recently the Regional Studies Association Annual Policy Conference, Coventry, 2009.

${ }^{2}$ Coventry University Business School, UK, and Department of Economics, University of Warwick, UK, respectively. Corresponding author: David Bailey. Email: david.bailey@ coventry.ac.uk
} 
(Glaeser, 2010; ODPM, 2006), it often appears as a centre of crisis in mature 'developed' regions at least in the early $21^{\text {st }}$ century, with the economic and social landscape of cities in the 'developed' world having being transformed in recent decades by the processes of globalisation, technological change, deindustrialisation and tertiarisation (Sassen, 2006; MacKinnon et al., 2008). This sense of 'cities in crisis' predated the most recent financial crisis and credit crunch that has engulfed much of the world, with the latter exposing further the more deep-seated structural and strategic issues facing our cities.

How are we to reconcile the two, probably valid, but seemingly paradoxical, observations of 'cities in crisis' and 'cities as engines of growth'? If indeed the city offers the potential for dynamism and economic growth then it may be viewed as a crucial site for industrial policy, provided that a developmental basis for economic policy is seen as a relevant focus. Furthermore, the appearance of the city as a centre of crisis in 'mature' industrial regions at least may mean that the policy for growth should be directed elsewhere, or it may mean that the costs imposed by an unregulated market economy disproportionately affects such cities' development. Clearly history matters, and recent history has witnessed the precipitate decline of many of the 'old' industrial cities of the developed world, in the United States, Japan, Western Europe, and various countries of European settlement, while yet others still manage to flourish (Glaeser, 2010). Recent history has also seen the emergence of large dynamic cities elsewhere in the developing economies, notably recently in China and India, following the earlier growth of the Pacific Rim countries. ${ }^{3}$

The paper is structured as follows. Section 2 highlights a core element of Jane Jacobs' work on the city; her view that the city is a centre of innovation, experiment and ideas where small scale is seen as functional, and where diversity is critical for creativity and development. Section 3 details how many of our 'old' industrial cities like Birmingham have over time shifted away from such a diverse economic base and have become dominated by large corporate entities, with a resulting stagnation which can be seen in manufacturing job losses, unemployment, worklessness, and often low-wages for those

\footnotetext{
${ }^{3}$ Global urban population growth has been estimated at some $2 \%$ per annum over $2005-2010$, but this figure conceals a sharp contrast between growth rates in Western Europe and Japan (0.4\%), the United States $(1.3 \%)$ and Australia (1.2\%) on the one hand, and China (2.7\%) and India $(2.3 \%)$ on the other (UN Population Fund, 2007: 90-93).
} 
who do manage to find new work. Classic policy responses have been to 'reimage' the city and attract mobile investment in an attempt to boost 'competitiveness', but often with disappointing results and at the cost of heightening vulnerability and fuelling uneven development. We argue that such policy measures risk repeating mistakes of earlier periods by concentrating development efforts on large powerful actors, especially transnational firms, as it is an over-reliance on such actors which has been intimately involved in the creation of the structural problem of cities in the first place, and which can crowd out the diversity and democracy which, we argue, cities need to flourish. Section 5 brings in a strategic choice perspective to suggest that a deeper restructuring is required, and one which challenges concentrated strategic decision making in modern transnationals so as to again diversify our cities and re-energise their creativity. Section 6 offers some initial thoughts on implications for industrial policy for cities in this context: building new industrial districts; developing high skill ecosystems; and fostering multinational webs of cities. Taken together, these suggest the need for much greater attention in industrial policy to the city itself and to ensuring the conditions exist in cities for creativity and development to flourish - a diverse and democratic economic system.

\section{City Dynamism and Diversity}

Agglomeration and external economies are traditionally seen as having underpinned the 'competitiveness' and growth of places including cities, drawing on their industrial specialisation and cumulative competence building. But more recent studies have stressed how the resilience of places and regions (see Oliver et al in this volume) - that is the ability of places to absorb, adjust, respond and ultimately outlive external shocks rests on the diversity of the economic base (see Andreosso-O'Callaghan and Lenihan in this volume). In particular, diversity appears to matter in a number of ways. Firstly, a diverse economy can be more resourceful in facing external shocks as it can rely on a wider set of skills, knowledge and competences which can be recombined and reintegrated. $^{4}$ Secondly a diverse economy offers the opportunity for Jacobian economies, and hence be more innovative and creative through serendipitous crosssector spillovers (see De Propris and Cooke in this volume). In relation to cities in particular, evidence suggests that large cities can maintain a long-term dynamism but

\footnotetext{
${ }^{4}$ A 'related variety' argument; see Boschma, 2005; Boschma and Frenken, 2006.
} 
only when they are sufficiently diversified to support this (see Glaeser et al, 1992). As Glaeser (1994, 9; our emphasis) notes, while physical closeness contributes to the flow of ideas, "the urban environment can foster the unexpected combination of seemingly unrelated ideas that may provide the most important forward leaps of knowledge". City decline is evident where this sort of diversity has not been maintained: Detroit (US) and Birmingham (UK) may be cases in point, their precipitate decline connected with a mono-sectoral profile, with a heavy concentration on the auto industry in both cases, ${ }^{5}$ while Krasnoiarsk-26 would be a perhaps more extreme case of a highly monosectoral city from a so called planned economy. ${ }^{6}$

In developing this paper we have been much influenced by the writings of Jane Jacobs (1961; 1969; 1984). While her ideas did not receive much attention from economists for many years, one central proposition of Jacobs (1969) - notably her emphasis on the role of the urban in the transfer of knowledge was picked up by mainstream economists (e.g. Romer, 1986; Lucas, 1988). In particular, Lucas (1988) developed this element of Jacobs' work and argued that cities are critical in thinking about human capital, knowledge and growth. In so doing, he brought to the study of growth economics the central idea that cities can play a key role in facilitating the accumulation of knowledge spillovers in the growth process (Glaeser, 1994). One dimension of Jacobs' inspirational writings thus fitted neatly into the new mainstream economic theories of the 1980's and 1990's, but we would suggest that her analysis and observations went much further. In particular, Jacobs saw the city as a centre of innovation, experiment and ideas where small scale is seen as functional, as portrayed in the anarchist literature (see Woodcock, 1975). In so doing, Jacobs rejected top-down planning by elites, whether governmental or corporate, and in contrast celebrated the grass-roots, with a recurring theme in her work being "the need of cities for a most intricate and close-grained diversity of uses that give each other constant mutual support, both economically and socially, and city

\footnotetext{
${ }^{5}$ Whereas Detroit and Birmingham have not received the core investment in the industry necessary to secure its long term dynamism, German and French auto firms - with government support - have essentially maintained this. While they have moved some assembly activity off-shore, they have maintained a strong engineering, research and development, design and marketing base in their home cities of Stuttgart, Munich and Paris, and such countries and regions have also attracted high-level activities from foreign auto transnationals in search of highly skilled workforces; e.g. the Korean auto firm Kia locating a design and development base in Frankfurt.

${ }^{6}$ Glazyrina (2000) notes that Krasnoiarsk-26 had a golden age from 1958 to the early 1980s as a centre for Soviet nuclear weapons production, but could "not adapt to changed circumstances and operate in conditions of a market economy" (ibid; 200). It is seen as a "City without a Future", despite possessing "significant scientific potential".
} 
planning and design must become the science and art of catalyzing and nourishing these close-grained relationships" (Jacobs, 1984; 24). Some validation for Jacobs' argument came from Glaeser et al (1992) in their econometric analysis of panel data for large cities, and industries in large cities, in the United States for the period 1956 to 1987: local employment growth was aided by city industrial diversity and competition within industries for those cities.

But as already noted, Jacobs extols the virtue of the city which grows and develops without top-down central direction, either governmental or corporate: the successful city is an outcome of the many decisions of its population. Yet the reality in the case of many cities in the United States, and for other countries, is that they are subject to the dominance of big and powerful actors, notably transnational firms. We argue that this is the root cause of the crisis affecting our cities, with the latter suffering the consequences of strategic failure (see below); that is a failure to determine the strategic direction of production, and thereby to determine the evolution of the economy, in the broader interest - "in the interest of the community at large" (Cowling and Sugden, 1999; 361). Thus cities should be seen as a priority focus for industrial policy, because of the potential rewards associated with the creativity of the city and given its role as a driver of economic growth which is not currently being fully realised, but also because of the present needs of many 'old' cities in real crisis.

We can see the city as a lynch-pin of development, as a focus of new ideas springing from the intensity of interaction of people within a specific location. But this proximity should not be seen as purely locational, for out of this intense interaction of different peoples and their different ideas emerges a consensual view of ways forward which reflects a new mental proximity which in turn allows further development of mutual dependency, in line with the ideas of Sacchetti and Sugden (2006). This free interaction between people is a very different process from that of a 'network of direction' reflecting the aims of those powerful groups, such as the elite at the top of corporate hierarchies, who seek to strategically control the process of development. The city, when allowed to work successfully, provides the environment we see as essential for a 
more democratic dynamism rather than an imposed, and thereby lesser, top-down (and vulnerable $)^{7}$ dynamism reflecting the wishes of an elite minority.

But is the city dying? Has the development of new technology allowing easy and cheap communication rendered the city obsolete? There are two possible effects: electronic communication substitutes for face-to-face contact and/or electronic communication complements face to face contacts. The first would reduce the role of the city, the second would enhance it. Complementarity has been found to be the dominant effect for large US cities at least, as suggested by Gaspar and Glaeser (1998), and Glaeser (1998). The future of the city would seem more secure if this is indeed the case, ${ }^{8}$ and Gaspar and Glaeser (1998) also note the high level of agglomeration in Silicon Valley. ${ }^{9}$

Going back to Jacobs' view that diversity matters for creativity and development it is necessary to recognise that some recent empirical results do not appear to support that view. Henderson (2003), for example, estimates productivity at the plant level using urban panel data and finds that city specialization, rather than diversity, matters. Yet knowledge spillovers between industries and clusters relate to new products or new varieties of old products, or new combinations of ideas across sectors. Perhaps the plant level productivity estimates of Henderson are not able to capture this qualitative - often cross-sectoral - effect; rather, such analysis requires a hedonic index of productivity (on the latter see Cowling and Vernon, 1996; Triplett, 2001).

\section{The Cities' Jobs Deficit}

A good example of an earlier period of city diversity, innovation and growth might be Birmingham during and immediately after the industrial revolution; a 'city of a thousand trades' with considerable diversity and innovative ferment. But much later the city became dominated by one sector (auto) and giant firms, and - like other UK cities outside London - has suffered over the last forty years from a dramatic process of deindustrialisation and relative economic decline. The impact of the latter is highlighted by Barber and Hall (2008) who stress that Birmingham's poor performance from the

\footnotetext{
${ }^{7}$ On vulnerable capitalism see Bailey and Cowling (2006).

${ }^{8}$ Recent empirical work showing proximity to higher-tiered urban centres is an important determinant of job growth is supportive of this conclusion, see Partridge (2008).

${ }^{9}$ Of course this observation may fit the argument of the previous footnote: it is exactly where we have diffuse developments like Silicon Valley that proximity is seen to be essential.
} 
late 1960s was indicative of long term structural decline rather than any cyclical problem, with significant contributors to decline including an over-concentration on the auto sector and low levels of investment and productivity. Indeed, between 1965 and 1981, Birmingham and the West Midlands lost some 370,000 manufacturing jobs, and in the decade 1971 to 1981 over $40 \%$ of the city's auto-related jobs were lost (Spencer et al, 1986). By 1981, GDP per capita of the region had fallen to $10 \%$ below the UK average, making Birmingham and the West Midlands the second poorest region in the UK, after Northern Ireland (ibid).

More broadly, in a telling example of the depth of the urban problem in the UK, Turok and Edge (1999) calculated that between 1981 and 1996, the twenty major cities in Britain lost half a million jobs, equivalent to about $25 \%$ of their male labour force, compared to a net gain of 1.7 million elsewhere, with such cities transformed from being major centres of employment to centres of non-employment, under-employment and social crisis. We would expect Britain to be an extreme case within Europe, given that we are associating job loss with the strategic decisions made by elites within transnational firms operating in a 'free market', but it is clear that unemployment in Europe as a whole remains high and particularly so in large metropolitan areas. However, it is also the case that the decline in jobs in British cities is not entirely represented in the growth of urban unemployment. There has been substantial growth in the economically inactive male population in British cities: even before the financial crisis that unfolded with such profound effects from 2008 onwards, one in six working age households had no adult in paid employment (Kemp et al, 2004). The larger industrial conurbations in Britain have been the worst performers as far as the sum of unemployment and inactivity is concerned, with Glasgow, Coventry and Merseyside, excluding Liverpool standing out as the worst for the 1990s (Webster, 1999). This decline in job prospects was associated with lower life expectancy and an increasing gap between the industrial cities and less urban areas. In fact no industrial cities featured among the areas with highest life expectancy (Office of National Statistics, 2004).

While The State of the Cities report (ODPM, 2006) suggested that many English cities were poised to again become "motors of national advance", more recent evidence has again highlighted their poor record on jobs and worklessness. The Centre for Cities 
(2009), for example, estimated the scale of the 'jobs deficit' facing England's cities, and suggested that even before the most recent recession unfolded, over 500,000 more jobs would have been needed simply to raise such cities' employment levels to the national average. The most recent recession and financial crisis has added to this profound problem, with the socio-spatial impact of unemployment disproportionately concentrated in the urban centres of the Midlands and North of England, Wales and Scotland (Clayton, 2011). And on a wider measure of joblessness (defined as the officially unemployed plus hidden unemployed such as discouraged jobseekers), Fothergill (2009) has highlighted how that crisis and recession has again impacted most on the old industrial areas, such as Birmingham, Wolverhampton and Sandwell, where the real joblessness rate was by 2009 well above $15 \%$.

In fact, in the UK job creation displays severe regional as well as intra-urban imbalances, with high-skill/high-wage jobs created being skewed towards London and the South-East, with far smaller 'islands' of prosperity in cities elsewhere (Glasmeier et al., 2008). And within cities, urban regeneration favouring high-skill service sector jobs has primarily occurred in city centres, especially in those cities seen globally as service 'poles' or 'nodes', such as London - or more widely Seattle, Hong Kong, Barcelona or Milan (van Winden, 2008; Gospodini, 2009). In contrast, 'regeneration' in the suburban centres of UK cities has often amounted to little more than the building of supermarkets and its association with low-wage, part-time, low-skill jobs (Nolan, 2004), where policy makers have championed the "importance of retail as a creator of jobs" in a wider context of declining manufacturing (Dixon, 2005: 171). In such cases, efforts at 'regeneration' may actually serve to widen inequalities (Young et al., 2006). Many lesser-skilled workers leaving declining industries - largely concentrated in outersuburban areas - have therefore been at risk of long-term unemployment, underemployment, or of leaving the workforce entirely. More broadly, as Turok (2010) notes, people who have re-entered work have struggled to find permanent and/or rewarding jobs, being "trapped in low-paid jobs or forced to move in and out of successive temporary posts" (ibid; 43). Witness, for example, the precarious labour market position, lower pay and lower satisfaction levels of former car workers in Birmingham after the MG Rover closure and the 'lift and shift' of production to China (Bailey et al, 2008; 2010). 
In response, there has been much debate on the emergence of the 'post-industrial city' (Gospodini, 2009), and the need for policy makers to embrace urban revival (van Winden, 2008) if traditional industrial cities are to have a viable future, whereby industrial cities 'reinvent' themselves and provide an accommodating environment for growth sectors (and hence jobs) in finance, IT, high-value services or other "desirable" sectors such as the creative and cultural industries (Mommaas, 2004; Gospodini, 2009). The resulting 're-imaging' of cities has been a key theme of modern place-marketing efforts by city governments in a wider context of "inter-urban competition within globalisation and increasing international capital mobility" (Young et al., 2006: 1691). Whilst recognising the efforts of many policy makers to improve their urban environments, we argue that this race for mobile investment is both superficial and risks repeating mistakes of earlier periods by concentrating development efforts on large powerful actors, especially transnational firms. For it is an over-reliance on such actors which has been intimately involved in the creation of the structural problem of cities in the first place, and which can crowd out the diversity and democracy which, we argue, cities need to flourish.

As Bristow (2010) succinctly notes, this quest for so-called competitiveness "creates huge vulnerability for regions that become overly dependent on a small number of large multinational firms, and gives large corporations huge power in relation to public policy" $(2010 ; 31)$. With it comes the dangers that policy serves external actors and not local communities, fosters a zero-sum 'arms race' of competitive subsidies, fuels speculative development which fails to address underlying economic problems, and fosters a narrow focus on a location's assets rather than development (ibid). The opportunity costs of public funds being used to prop up such projects is lost investment in areas such as housing and education; as Bristow concludes, "the obsession with competitiveness and the desire to outperform rivals may fuel the uneven development at the heart of capitalism, which devalues one place in favour of another" (ibid).

\section{The Underlying Problem: Transnationals, Strategic Failure and a Double Dualism}

There are many more or less proximate explanations for the problems facing European cities in recent times, but these are generally underpinned by their underlying economic 
structure, a structure largely created by the activities of the major corporations. ${ }^{10}$ The particular theme of this paper is built on the strategic choice perspective developed by Cowling and Sugden (1994, 1998, 1999), Sugden and Wilson (2002) and Bailey et al (2006). It argues that to understand the city and its potential requires us to go behind the scenes to establish the roots of dynamic economic performance, and the precipitate decline in many 'old' cities in the early $21^{\text {st }}$ century. In particular, we argue that a key link between the old industrial world and the new which we see as providing a fundamental explanation, at both ends of the development process, is the modern transnational corporation. By switching investments around the world these large and powerful firms are able to determine the global distribution of economic activity (Dicken, 2010). The transnationals can, at one and the same time, deindustrialise the 'older' industrial countries (and cities therein) and industrialise the 'new', within themselves. And within themselves, only certain actors matter in this process: strategy within the corporation, that is the direction and type of development, is determined by those who control the corporation. Exactly who controls the corporation and determines strategy in this way has been the subject of much debate amongst economists. Some argue that corporate control remains with senior managers, others focus on certain powerful shareholders, whilst others see such groups as basically the same people anyway. ${ }^{11}$ Nevertheless, whilst recognising the possibility of 'heterogeneity' across firms in terms of the exact composition of elites, there is a general consensus amongst economists that control of firms rests with a subset of those having an interest in a firm's activities, and certainly does not rest with the workforce. Rather, strategic decision-making is concentrated in the hands of an elite (Cowling and Sugden, 1999).

Others involved and affected by such strategy may object but ultimately they cannot reverse such policies. The fundamental point is that a small elite will dictate strategy and thus such strategy will reflect their aims and ambitions: the aims and ambitions of others will be neglected. A distinction can thus be drawn between 'corporate' and 'community' strategies. 'Corporate' strategies are viewed as strategies for development conceived by and in the interests of strategic decision makers within giant firms, whereas 'community' development strategies are those devised by and in the interests

\footnotetext{
${ }^{10}$ Rothschild (2005) provides a succinct account of this new world and explains why it creates the need for a new approach by policymakers

${ }^{11}$ For a recent survey of the literature see Branston et al (2006), Tirole (2001), and Bailey and de Ruyter (2007).
} 
of a wider set of actors in the community (Sugden and Wilson, 2002). The implication is that if strategic decision-making in modern transnationals is the preserve of only a few, there arises the potential for 'strategic failure', where the objectives of the elite making strategic decisions conflict with wider interests in society, with the result that the economic system fails to deliver the most appropriate outcomes for the community. The risks of such strategic failure are seen as more likely when deregulation and liberalisation create increased freedom from intervention by government, workers and others (greater 'negative' freedom) for strategic decision-makers in increasingly dominant and mobile firms over strategic issues such as investment, research and development, output, employment, advertising and marketing expenditure and so on (see Bailey and de Ruyter, 2007). Precisely because so-called 'free markets' concentrate strategic decision-making in the hands of elites, "development paths based upon an especially prominent role for transnational corporations are inherently problematic" (Cowling and Sugden, 1999).

While the decline of many major industrial cities in the 'developed' world is related to many more or less proximate factors, in turn related to a changing technology of production as well as changes in the conditions of international trade, this decline is we argue - underpinned by the strategies of the major corporations, and these are in turn determined by the aims and ambitions of their controllers, a small minority of those involved within these powerful entities. For example, despite widespread stakeholder opposition and protest, the Kraft takeover of Birmingham-based Cadbury and the subsequent relocation of head office functions to the US and Switzerland, went ahead in 2010 - and with no government intervention. While governments are not without power, in an increasingly global world national governments like that in the Britain are rendered increasingly powerless if they accept the rules of the game laid down by the transnationals, and of course there are many compelling economic and political reasons for doing so.

It is therefore the case that strategies for development of the developed world - and the cities within them - have not met the aims and ambitions of the majority of the population within them. Such strategies have not been in the wider interest - the public interest (Branston et al, 2006, Bailey and de Ruyter, 2007). As a matter of history, technology and communications have developed to allow this global development of 
transnational companies to exploit the huge supply of labour in the underdeveloped world: the integration of China into the world market economy has almost doubled the available labour force (and the rapid urbanisation of China and the massive shift of people from countryside to city in China is continuing this trend). The playing out of transnationals' strategies has involved both centrifugal and centripetal development: work has been put out by transnationals (either within the firm or under their control via sub-contracting) from the older industrial centres to countries where labour costs are much lower (centrifugal forces), but high-level strategic control over such work has been increasingly brought to the centres of the new transnational system (centripetal forces).

But what of the role of the 'old industrial' city? As the location of rapid economic growth has switched, so many of the industrial cities of the developed world have declined because the transnational corporations can see little advantage to such locations when faced with the alternative of cities elsewhere with significantly lower costs, whether they be in lower cost locations within trade blocs such as the EU (such as central Europe) or in 'developing' countries. Of course, if the cities of the older industrial world are able to establish new industries in response to this threat then a future can be fashioned for them in the new world. So long as the headquarters of the transnationals remain in the older industrial cities they will require services, associated with both production and consumption, for their future at such locations. ${ }^{12}$ Global production requires management, marketing, research and development and this will tend to be centralised at the headquarters site for some time; equally consumption out of the income generated by the corporation will demand local retailing, entertainment, medical and educational facilities. Opportunities, however, will be limited and not congenial to the interests and abilities of larger sections of the community: those who work for the corporation at the centre will require specific skills not readily available within the labour force displaced with deindustrialisation.

Overall, the large transnationals will have only a limited loyalty to their origins: they will seek profits on a global basis with limited restrictions, and will also push for

\footnotetext{
${ }^{12}$ Although even this is not guaranteed given the highly active market for corporate control especially in co-called 'Anglo-Saxon' economies; witness the Kraft takeover of Cadbury noted above and subsequent head office shift out of the UK. See also GM's recent active consideration of shifting its headquarters from Detroit (The Guardian, 2010).
} 
institutional frameworks which minimise any such restrictions. Rather, local long-term development requires a production system willing and able to invest in the locality in the widest sense: to maintain and develop the local infrastructure in terms of human capital, as well as physical capital. Transnationals will take human capital wherever they find it at a minimum cost and will be interested in government investing in it, wherever it has such influence. And the subversion of decision-making within the firm in the interests of the few can mean that the wider public interest within the city is ignored in strategic decision making. Thus corporations may pursue a globalisation strategy which may involve relocation of production from the older industrial cities to the newly industrialising cities of the emerging countries without the views of those workers in the old centres of production playing a role. We should not be surprised if the outcome is the deindustrialisation of European industrial cities with the inevitable consequences for jobs. Transnationals are capable of producing 'pain as well as pleasure' in the context of the free market, as it has developed.

As a rough approximation a double dualism has been created. Within the market economy there is a core, the OECD countries, and periphery, the rest of the world. As Hymer (1972) put it there is a law of uneven development established, partly the result of the transnational corporations, ${ }^{13}$ this is the "tendency of the system to produce poverty as well as wealth, underdevelopment as well as development" (Hymer, 1972: 114). Our point is that as well as being true at the global level between the developed and developing nations, the transnational corporations have also produced a similar gap within the developed world. We can observe under-development as well as development within the 'advanced industrial countries' (AICs) and even within London and New York and Paris as well as within the UK and the United States and France.

\footnotetext{
13 Hymer (1972) made the critical connection between the structure and organisation of giant transnational firms and the structure and organisation of the broader international economy resulting from their pre-eminence. In his law of uneven development, low-level day-to-day activities (level III) are spread in search of low costs and market access, the coordination of such activities (level II) is more geographically concentrated given the need for skilled workers and communication/information systems, and top-level management responsible for goal determination and planning (level I) is concentrated in major cities. The latter become the "major centers of high-level strategic planning" (Hymer, 1972: 115) whilst lesser cities would be organised on a hierarchical basis ranging from bases for regional headquarters down to sites dealing with merely day-to-day operations.
} 
So within the core there is another core-periphery, and the question "why are we so rich and they so poor?" (or vice-versa) takes on an international dimension, but also an intranational one, and perhaps increasingly so. The centrifugal and centripetal tendencies connected with this new globalism, with production leaving the old manufacturing cities of the core for the low wages of the periphery, and control over this process being concentrated within the core, provided the backdrop for the decaying old manufacturing cities unambiguously damaged by this process. However side-byside with them are the so called command cities or global cities (Sassen, 1991). These are centres of corporate strategic decision-making, where corporate headquarters are concentrated in a few of the large cities of the world: New York, London, Tokyo, Paris have the largest concentrations, with Shanghai and Mumbai emerging as new players. ${ }^{14}$ These cities have gained from centripetal developments in terms of headquarters employment and employment in business services related to headquarters functions, but also from the employment creating effect of the (sometimes huge) salaries and bonuses received within headquarters, which are spent locally on services; medical, recreational, entertainment and so on. Yet the prosperity of these cities lies alongside the poverty of significant minorities, especially male manual workers or former workers, largely untouched by the wealth generated within the command city. We have seen the resentment built up by the juxtaposition of this rising local inequality, for example in the riots within the banlieue of Paris, and more positively in the campaign for a living wage in cities such as London (Wills, 2009).

\section{A Way Forward: The City as a Priority Focus for Industrial Policy?}

It is clear from our analysis so far that policies directed at the cities had been less than adequate, even before the most recent crisis unfolded. Tactical policies have varied but have often involved measures for 'reimaging' cities and attracting and subsidising investment by global corporations (as noted above) or for small firms. Typically corporations take the money and move on when it becomes attractive to do so ${ }^{15}$ - we have seen this in cities around the industrial world - and small firms often have very

\footnotetext{
${ }^{14}$ Sassen (2006) defines global cities as "strategic sites for the management of the global economy and the production of the most advanced services and financial operations" - Level I activities in Hymer's classification.

${ }^{15}$ Dell's assembly operations in (or rather now out of) Limerick is a recent example. See Lenihan and Bailey (2009): 'Intervention essential for those who lose Dell jobs', Irish Times (opinion) Oct $27^{\text {th }}$.
} 
low survival rates in the hostile environments created by the dominant corporate players - they only survive when they play to the rules set by the giants. ${ }^{16} \mathrm{We}$ are confronted with decaying or decayed manufacturing cities as well as decaying areas in 'command' cities; these are different but connected problems which we argue have their roots in the strategic failure related to the dominance of major corporations in the market economy. At the heart of the free market system we have seen systemic failures which have reduced the fundamental dynamism of cities. It would therefore seem essential to explore possibilities of creating development paths for cities which avoid such failures. The obvious response is to try and tackle the source of the failures head-on: to look at ways of involving more of those affected by strategic decisions in the process of making these decisions, and to design ways of democratising strategic decision making. This would be a long term project and highly political. In part this would need to be sought within the hierarchical structures of the big corporations and would need the monitoring of the activities of these firms and the democratisation of decision making processes (Bailey and de Ruyter, 2007). A further dimension of policy would be the nurturing of an alternative structure of production characterised by symmetrical horizontal relationships rather than asymmetric, hierarchical relations seen within the dominant mode of production today: some form of small firm production. Thus we would seek to convert the present essentially tactical approach to the problems and potential of the cities into a much more strategic role for economic policy (and indeed one which considers strategic decision making at its core) aimed at restructuring the city economy to enable the full realisation of its potential and dynamism.

With this view of the world, agglomeration is necessary but not sufficient for development. Rather, what is required is a more democratic and diverse base, where place and the locality can be more effectively introduced into local economic strategy. Space precludes a full consideration of the implications of such an approach for a new industrial policy, but we will make some initial proposals in line with this aim. In particular, we would highlight the imperative for a more place-based industrial policy to: (1) create more democratic and diverse economic structures, drawing on appropriate examples where possible, such as the lessons offered by experiences in industrial districts, but having a coherence within the city; (2) creating "self-sustaining high skill

\footnotetext{
${ }^{16}$ Occasionally we see small firms succeeding but they are typically acquired by their larger rivals and become, often unsuccessful, divisions of these corporate giants; see Ravenscraft and Scherer (1989).
} 
ecosystems" based on local universities, research institutions and other actors, in line with the ideas of Finegold (1999); (3) creating multinational webs of cities and regions facing similar challenges (see Cowling and Sugden, 1999), and by these various means and processes reshaping the economic basis of the city, away from a dependence on the strategies of the major transnational corporations to a collective self-reliance of multinational communities. We shall highlight each of these in turn as specific possibilities for an industrial policy that attempts to reinvigorate the city.

\section{- Building 'New Industrial Districts'}

Clearly, the presence of small firms is no guarantee of socially optimal outcomes, but intuitively, democratic strategic decision making appears more feasible if an economy comprises small and medium sized firms. Moreover it is noticeable that much recent literature has focused on allegedly successful groupings of small firms, especially with respect to innovation, in the industrial districts of Italy (for example Becattini et al (2003, 2009). The idea of groupings of small firms is appealing because it is often argued that technology requires production on a large scale to minimise cost and it is notable that in some significant cases small firms have been able to cooperate to achieve these economies without there having to be concentration of production in one large scale hierarchical organisation.

Yet there has been evidence recently that some of the industrial districts (for example in Italy) have been experiencing real problems, related to globalisation and the emergence of new competition (Becattini et al, 2009). This may be in line with the evidence from US cities provided by the econometric analysis of Glaeser et al (1992). As we have remarked they found evidence that city success (in terms of employment growth) was linked to industrial diversity within the city, in line with Jacobs $(1969,1984)$. In a recent debate about Jacobs on the role of the city in economic growth, Polese (2005) argues that agglomeration is not the essence (although as we have noted, Jacobs provided a richer analysis than this would suggest). Agglomeration alone is not sufficient for growth and development; rather diversity is necessary and this springs from a diffuse industrial base, which is suppressed by corporate control. Simply talking of cities as sites from which dynamic agglomeration economies will spring does not 
identify the essence of the problem (i.e. concentrated strategic decision-making). Growth and development requires a more democratic element than corporate control allows, witness the quote we give from Jacobs (1984) at the start of this contribution. We need to explain diversity and not just treat it as an independent variable in growth economics. It would seem that in the long-run (Glaeser et al were looking at a 30 year period) success requires the stimulation of variety. Faced with repeated shocks cities need to change their industrial structures and a diversified industrial base contributes to this via the cross-fertilisation of ideas as Jacobs has suggested (see also De Propris and Cooke in this volume). Looking historically, for example at the industrial revolution in England, Jacobs saw Manchester as failing to maintain its success of the $19^{\text {th }}$ century: it was seen as too specialised. In contrast, Jacobs saw Birmingham as the city of the future with its apparently more diffuse and diversified industrial base. Yet as noted above, Birmingham has not sustained its success in the late $20^{\text {th }}$ and early $21^{\text {st }}$ century, following its loss of control over industrial development. With the takeover of its industrial base by transnational corporations, strategic decision making has quite literally moved elsewhere. And as noted, Birmingham now has the highest unemployment of the eight biggest regional cities in Britain. London is now unique (in England) in having the diversity required for dynamism ${ }^{17}$, which may also be linked to its size and 'connectedness'.

With these sorts of observations in mind it would seem constructive to consider the possibility of creating city structures within themselves reminiscent of industrial districts, less specialised in the usual sense, but having a coherence within the city, mingling many different aspects of the city to create new industries on which future development of the city might be based via cross-sectoral fertilisation. This would involve intersecting webs of small firms, including different areas of activity which have elements of complementarity - for example the digital technology platform with its links into design, media, IT, telecommunications and so on; this could comprise a large group of production units which taken individually are quite small but which taken as a group constitutes a production process on a large scale. The aim would be for units to cooperate or network by providing mutual support in a process which also promotes the emergence of new and rival production units; a system combining

\footnotetext{
${ }^{17}$ Whether this survives the financial crisis, is an open question. It raises the question of London's possible over-specialisation on financial services which is now being raised.
} 
elements of rivalry and cooperation within it, yet constantly evolving. To achieve this will require policy operating with a light touch, eschewing monopoly positions, maintaining open access to knowledge and critical financial support especially for micro-firms, allowing for constant change. Financial support would not imply subsidy for the large and dominant, but credit at critical times for the evolution of the small and new: something like a Grameen bank tailored to the needs of the European city, creating a culture where the emphasis is on people, individually and collectively evolving and trusting their ability to find many and varied development paths.

Over the long-run, the city needs to adapt and change in response to a multitude of shocks: a diverse industrial structure allows it to do this, and an industrial policy for the city should be orientated towards fostering such diversity. Short-run bursts of city growth have been made in the past by specialised cities but to be sustainable - or 'resilient' in the contemporary discourse - appears to require this diverse base: Jacobs was right in the long-run. The evidence suggests, at least for US cities, that important knowledge spillovers occur between industries, in the long-run at least, rather than within industries. The essence of Jacobs is diversity and there is a need to ensure that this is the essence of a new industrial policy. Such policies, by supporting a variety of industrial processes will also serve to support a variety of talents and thus avoid any tendency for people to be excluded from the development process. ${ }^{18}$ These special sorts of industrial districts would act as havens away from corporate dominance and repression, allowing experiments to take place, ideas to be hatched, communications between people with ideas to take place. To avoid decline, to promote success, a city needs continuous stimulus and must remain open to the entry of firms and ideas.

Such issues may be especially relevant to our 'old' industrial cities where there is considerable potential for 'phoenix' industries to emerge from the ashes of old manufacturing industries. As Christopherson notes (2010; 79), where this has happened there is not one dominant employer but rather many small and medium sized firms (i.e. a diversity of firm sizes as well as sectors). These often produce sophisticated components sold on to equipment manufacturers in fields as diverse as defence and

\footnotetext{
${ }^{18}$ In line with Sen's (1999) concept of substantive freedom which embodies "the freedom to participate in the social, political and economic life of the community".
} 
health, and are often seen as "enabling industries" given their cross-sectoral linkages. For phoenix industry start-ups, "the incubator is not a technology park; it is the whole urban region" (ibid) - again suggesting the need for diversity and cross sector fertilisation. This in turn links to the need for a high skill ecosystem.

\section{- Self-sustaining High Skill Ecosystems}

As part of a system of new industrial districts it would be interesting to explore the possibilities of developing high skill ecosystems (see Finegold, 1999; Alcorso and Windsor, 2008). Such systems are seen to require four requirements: a catalyst, ongoing nourishment, a supportive host and a high degree of interdependence among actors. Finegold (1999) saw the UK possessing many of the ingredients (good universities, telecoms, science parks, culture) but some weaknesses (outflows of scientific stars, limited seed corn funds, poor links between firms and universities. Obviously creating successful high skill ecosystems will not solve the low skill equilibrium problems of the UK noted earlier, but Finegold argues that the policy solution is not to curtail them but rather to improve educational levels for those unable to benefit and to redistribute the wealth created to create living wage jobs for the lower skilled in sheltered parts of public and private service sectors.

\section{- $\quad$ Multinational Webs of Cities}

To be critical of the existing transnationalism of the major corporations is not to advocate a narrow, national or intranational approach to policymaking. The development of multinational webs of small firms is part of an alternative development path where people, and thus economies and societies, are able to realise their full potential (Cowling and Sugden, 1999 and Sugden and Wilson, 2002). Instead of internationalising production by hierarchical control and the concentration of decisionmaking, as transnational corporations have done, the suggestions we are making would provide an alternative process which would be non-hierarchical and would foster a diffusion of decision-making: a grass roots, multinational process of evolution. Many European cities are facing similar problems; Edinburgh/Dublin; Glasgow/Hamburg; London/Berlin; Paris/Milan; and similar opportunities. Cooperating on a way forward through small firm webs at the level of production could lead to a wider and deeper cooperation of societies and cultures. Such a process could lead to the gradual reshaping 
of the economic basis for the city and offer new opportunities. Indeed, returning to the phoenix industries example, multinational cooperation between cities and regions would seem critical; as phoenix industry regions do not compete in the way that regions do when dominated by large firms, so they can benefit from strategic alliances. Christopherson (2010) gives the example of potential cooperation between Rochester in the US (with its expertise in lasers) and Sheffield in the UK (with its expertise in cutting technologies and steels), with the potential for fostering innovation and developing new markets; through such alliances the "cross-fertilisation of regionally based technical expertise may be possible" (ibid; 85).

\section{Conclusion}

In light of the evidence and arguments presented in this paper, it may be the case that the process of city decline can only be reversed by changing the very industrial and organizational structure of the city. Existing policies - for example in competing for mobile 'flagship' investment (which is anyway currently 'thin on the ground' in the current environment) - may anyway be no more than 'sticking plasters' on the problem identified here and may actually exacerbate problems of vulnerability and uneven development. We may have to go to the roots of the problem by releasing the city from the domination of the giant corporations, whether private or public, and encouraging the development of a more diffuse and diverse base, replacing the hierarchical system of our old cities with a more horizontal one. We argue that this particular relevance for the theme of this special issue, in that the most recent recession and crisis has again exposed the on-going process of decline which mature cities had anyway been undergoing in recent years. Building more resilient cities that are better able to weather 'shocks' requires a greater diversity in their industrial base, where the latter can also contribute to greater innovative dynamism via the cross-fertilisation of ideas as Jacobs has suggested.

From this perspective, city development is related to industrial development, and industrial development is related to city development. With this view of the world, agglomeration is necessary but not sufficient for development. Rather, what is required is a more democratic and diverse base, where place and the locality can be more effectively introduced into local economic strategy. Going forward, such a strategy requires that initiatives be pursued simultaneously at city, regional, national and pan- 
European levels. Democratic involvement in the economy needs to be developed at the city level but must extend outward to the European level otherwise actors (like the big corporations) with a pan-European perspective and competence will undermine any local autonomy. The transnationality of the major corporations enables them to pit community against community in seeking their own ends via a 'divide and rule' strategy. It is necessary to counter this power by creating an alternative powerbase with strong grass roots throughout Europe. Thus, in a long and difficult strategy, we can seek to transform a system of dependence into one of collective, self-reliance of multinational communities, "self interest as properly understood" through civic engagement, deToqueville, (2003).

\section{References}

Alcorso, C. and K. Windsor (2008) Skills in Context: a Guide to the Skill Ecosystems Approach to Workforce Development. Available at: http://skillecosytem.net/data/files/general/skills_in_context\%20(2).pdf

Last accessed $1^{\text {st }}$ February 2011.

Bailey, C Chapain, B Fauth and M Mahdon (2008) Life after Longbridge: Three Years on. Pathways to Re-employment in a Restructuring Economy. London: The Work Foundation.

Bailey, D. and Cowling K. (2006), Industrial Policy and Vulnerable Capitalism, International Review of Applied Economics, 20(5), pp 537 - 553.

Bailey, D, L De Propris, R Sugden and J R Wilson. (2006) Public Policy for Economic Competitiveness: An Analytical Framework and a Research Agenda, International Review of Applied Economics, 20(5): 555-572.

Bailey, D and A de Ruyter. (2007) Globalisation, Economic Freedom and Strategic Decision-Making: A Role for Industrial Policy? Policy Studies, 28 (4) 383-398.

Bailey, D, A de Ruyter and I Clarke. (2010). Private Equity and the Flight of the Phoenix 4? The Restructuring, Collapse and Impact of MG Rover in the West Midlands, Cambridge Journal of Regions, Economy and Society, 3(3): 367-382.

Barber, Austin and Stephen Hall. 2008. Birmingham: Whose Urban Renaissance? Regeneration as a Response to Economic Restructuring, Policy Studies, 29(3) 281-292.

Becattini G., Bellandi M., Dei Ottati G. and Sforzi F. (2003) From Industrial Districts to Local Development. Cheltenham: Edward Elgar.

Becattini, G, M Bellandi and L De Propris. (2009) Critical Nodes and Contemporary Reflections on Industrial Districts: An Introduction, in 
Giacomo Becattini, Marco Bellandi and Lisa De Propris, ed.s, A Handbook of Industrial Districts. Cheltenham: Edward Elgar.

Boschma, R (2005) Proximity and innovation. A Critical Assessment, Regional Studies, 39: 61-74.

Boschma, R and K Frenken (2006) Why is Economic Geography not an Evolutionary Science? Towards an Evolutionary Economic Geography, Journal of Economic Geography, 6: 273-302.

Branston, J.R., Cowling K. and R Sugden (2006) Corporate Governance and the Public Interest, International Review of Applied Economics, 20(2) 189-212.

Bristow, G. (2010) Limits to Regional Competitiveness, in J. Tomaney, ed., The Future of Regional Policy. London: The Smith Institute / Regional Studies Association.

Centre for Cities. (2009) Private Sector Cities: a new geography of opportunity. London: Centre for Cities.

Christopherson, S. (2010) Building "Phoenix Industries" in our old Industrial Cities, in J. Tomaney, ed., The Future of Regional Policy. London: The Smith Institute / Regional Studies Association.

Clayton, N. (2011) The Spatial Impacts of Recession, in Bailey, D and C Chapain, ed.s, The Recession and Beyond: Local and Regional Responses to the Downturn. London: Taylor \& Francis.

Cowling K and R Sugden (1994) Beyond Capitalism: Towards a New World Economic Order. London: Pinter.

Cowling K and R Sugden. (1998) Strategic Trade Policy Reconsidered: National Rivalry vs Free Trade vs International Cooperation, Kyklos, 51, 339-357.

Cowling K and R Sugden (1999) The Wealth of Localities, Regions and Nations: Developing Multinational Economics, New Political Economy, 4; 361-378.

Cowling K. and Vernon G. (1996) Productivity Growth, Product Quality and the production process, in D Mayes ed. Sources of Productivity Growth, Cambridge: CUP.

Currid E. (2007) The Warhol Economy : How Fashion, Art and Music Drive New York City. Princeton and Oxford: Princeton University Press.

deToqueville A. (2003) Democracy in America. London: Penguin.

Dickens P. (2010) Global Shift: Mapping the Changing Contours of the Global Economy. London: Sage. 
Dixon, T. (2005) 'The role of retailing in urban regeneration', Local Economy, 20 (2): 168-82.

Finegold D. (1999) Creating Self-sustaining High Skill Ecosystems, Oxford Review of Economic Policy, 15(1) 60-81.

Fothergill, S. (2009) The Impact of Recession on Unemployment in Industrial Britain. Barnsley: Industrial Communities Alliance.

Gaspar J. and Glaeser E.L., (1998) Information Technology and the Future of Cities, Journal of Urban Economics, 43, 136-156.

Glaeser, E.L. (1994) Cities, Information and Economic Growth, Cityscape, 1(1) 9-47.

Glaeser, E. L., (1998) Are Cities Dying?, Journal of Economic Perspectives, 12(2) 139-160.

Glaeser E. L., Kallal H., Scheinkman J. and A. Shleifer, (1992) Growth in Cities, Journal of Political Economy, 100, 1126-54.

Glaeser, E.L. (2010) America's Revival begins with its Cities, The Boston Globe, 30/12/2010. Available at: http://www.boston.com/bostonglobe/editorial_opinion/oped/articles/2010/12/30/americ as_revival_begins_in_its_cities/ Last asccessed 30/12/2010.

Glasmeier, A., Martin, R., Tyler, P. and Dorling, D. (2008) 'Editorial: Poverty and place in the UK and the USA', Cambridge Journal of Regions, Economy and Society, 1 (1): 1-16.

Glazyrina V. (2000) Krasnoiarsk - 26: A Closed City of the Defence Industry Complex, in J. Barber and M. Harrison The Soviet Defence Industry Complex from Stalin to Khrushchev. Houndmills: Macmillan.

Gospodini, A. (2009) 'Post-industrial Trajectories of Mediterranean European Cities: The Case of Post-Olympics Athens’, Urban Studies, 46 (5\&6): 1157-86.

The Guardian (2010) GM nearly quit Detroit says ex-Car Czar, 06/09/2010. Available at: http://www.guardian.co.uk/business/2010/sep/06/general-motors-bailout-rattnerobama Last accessed 15/09/2010.

Henderson, J. V. (2003) Marshall's Scale Economies, Journal of Urban Economics, 53(1): 1-28.

Hymer S. (1972) "The Multinational Corporation and the Law of Uneven Development", in J.N. Bhagwati (ed), Economics and World Order: From the 1970s to the 1990s. London: Macmillan.

Jacobs J. (1961) The Death and Life of Great American Cities. London: Jonathan Cape. 
Jacobs J. (1969) The Economy of Cities. Harmondsworth: Penguin.

Jacobs J. (1984) Cities and the Wealth of Nations. Harmondsworth: Penguin.

Janik A. and S. Toulmin (1996) Wittgenstein's Vienna. Chicago: Elephant Paperbacks.

Kemp P. et al (2005) Routes out of Poverty: A Research Review. York: Joseph Rowntree Foundation.

Lucas R. (1988) "On the Mechanics of Economic Development” Journal of Monetary Economics, 12, 3-42.

MacKinnon, D., Cumbers, A. and Shaw, J, (2008) 'Rescaling employment relations: key outcomes of change in the privatised rail industry', Environment and Planning A, 40: $1347-69$.

Mommaas, H. (2004) 'Cultural Clusters and the Post-industrial City: Towards the Remapping of Urban Cultural Policy’, Urban Studies, 41 (3): 507-532.

Nolan, P. (2004) 'Editorial: Shaping the future: the political economy of work and employment', Industrial Relations Journal, 35 (5): 378-87.

ODPM (Office of the Deputy Prime Minister). (2006) State of the English Cities. Volume 1. London: ODPM.

Office of National Statistics (2004) Life Expectancy Tables. London, HMSO.

Partridge M.D., Rickman D.S., Ali K., Olfert M.R. (2008) Employment Growth in the American Urban Hierarchy: Long Live Distance, The B.E. Journal of Macroeconomics: Contributions, 8, 1, 10.

Polese M. (2005) Cities and National Economic Growth: A Reappraisal, Urban Studies, 42(8) 1429-1451.

Ravenscraft D.J. and F.M. Scherer (1989) The Profitability of Mergers, International Journal of Industrial Organization, 7, 101-116.

Romer P. (1986) Increasing Returns and Long-Run Growth, Journal of Political Economy, 94, 1002-37.

Rothschild K.W. (2005) New Worlds - New Approaches: A Note on Future Research Strategies, Kyklos, 58(3) 439-447.

Sacchetti S, and R Sugden. (2005) The Governance of Networks and Economic Power: The Nature and Impact of Subcontracting Relationships, Journal of Economic Surveys, 17(5) 669-91.

Sacchetti S., Sugden R. (2006) "Mental Proximity in the Organisation of Industry", Institute of Economic Policy Development, University of Birmingham, September. 
Sassen S. (1991) The Global City. London: Princeton University Press.

Sassen, S. (2006), Cities in a World Economy. $3^{\text {rd }}$ Edition, Thousand Oaks, CA: Pine Forge Press.

Sen, A. (1999) Development as Freedom. Oxford: OUP.

Spencer, K., A. Taylor, B. Smith, J. Mawson, N. Flynn, R. Batley. (1986) Crisis in the Industrial Heartlands: a Study of the West Midlands. Oxford: Clarendon.

Sugden R, and J. Wilson. (2002) Economic Development in the Shadow of the Consensus: A Strategic Decision-making Approach, Contributions to Political Economy, 21, 111-134.

Tirole J. (2001) Corporate Governance, Econometrica, 69(1), 1-35.

Triplett, J.E. (2001) Hedonic indexes and statistical agencies, revisited, Journal of Economic and Social Measurement, 27(3/4): 131-153.

Turok I., and Edge N. (1999) The Jobs Gap in Britain's Cities: Employment Loss and Labour Market Consequences. Bristol: Policy Press.

Turok, I. (2010) Social Inclusion - Mixed Progress, Uncertain Prospects, in J. Tomaney, ed., The Future of Regional Policy. London: The Smith Institute / Regional Studies Association.

UN Population Fund (2007) State of the World Population: Unleashing the Potential of Urban Growth. Geneva: United Nations.

van Winden, W. (2008) 'Urban governance in the knowledge-based economy: Challenges for different city types', Innovation: Management, Policy \& Practice, 10: 197-210.

Webster D. (1999) Employment Convergence in 1999s Britain: How Real? Glasgow City Housing, August.

Wills, J. (2009) Subcontracted Employment and its Challenge to Labor, Labor Studies Journal, 34(4): 441-460.

Woodcock G. (1975) Anarchism. Harmondsworth: Penguin.

Young, C., Diep, M. and Drabble, S. (2006) 'Living with Difference? The 'Cosmopolitan City' and Urban Reimaging in Manchester, UK', Urban Studies, 43 (10): 1687-1714. 